\title{
NuEVo MUNDO, DIVERSIDAD Y GASTRONOMÍA DEL CARIBE SUR COSTARRICENSE
}

\begin{abstract}
Resumen
La comida caribeña incluye múltiples variedades gastronómicas, emparentadas por técnicas culinarias y una larga lista de ingredientes comunes, adoptados para la preparación de los alimentos usados tanto para eventos especiales, como en la nutrición cotidiana. Se realiza un recorrido histórico por las influencias caribeña y se ofrecen testimonios y recetas.
\end{abstract}

Palabras claves: gastronomía del Caribe, recetas de la tierra, intercambio de ingredientes, fusiones culinarias interculturales, diversidad.

\begin{abstract}
Caribbean cuisine includes many culinary varieties, related by cooking techniques and an adopted long list of common ingredients, use for the preparation of food for special events or for everyday nutrition. A historical journey is made by the Caribbean influences and offer testimonials and recipes.
\end{abstract}

Keywords: caribbean gastronomy, soul food, ingredients exchange, intercultural culinary fusions, diversity.

Carolina Jiménez.

Historiadora de arte, artista plástica y tiene una maestría en tecnología educativa. Realiza trabajo independiente en investigación de campo y recopilación de elementos autóctonos de la región de la Alta y Baja Talamanca donde reside de manera permanente desde hace unos 15 años. carolinajimenez@racsa.co.cr

\section{Introducción}

La historia de pueblos y personas se caracteriza por su dinámica constante de cambios y adaptaciones, así como su estudio y exposición son variables y susceptibles de reinterpretaciones. Hasta hace algunos años los territorios de la América continental con costa al Mar Caribe, se habían excluido de las definiciones de Región Caribe, la cual es indiscutiblemente insular, pero también continental. Los pueblos caribeños han llegado a reconocerse a sí mismos como tales al identificar un pasado común, aunque de orígenes variados, cuya interacción generó trasfondos culturales que se traslapan y re-encuentran en múltiples y variadas manifestaciones populares, como en la música, la danza, creencias y prácticas religiosas, conocimientos y usos similares de la medicina natural tradicional, costumbres y estilos de vida muy particulares y, ocupando un sitio muy importante, destaca la inigualable comida caribeña. 
En el Caribe se respira un aire singular aun cuando las nacionalidades, variedad de idiomas y regionalismos sea grande; la identidad caribeña la dicta ese exótico pasado tan inusitado y el efervescente ambiente común de cinco siglos de inten sa convivencia e intercambio, cuando personas, menajes, las exóticas especias del oriente, telas, plantas, las noticias, el vino, abastecimientos, libros, y más, transitaban exclusivamente por mar; hasta entrado el siglo XX la vida acontecía pendiente al continuo movimiento marítimo, y así, entre batallas y tormentas, soles y bendiciones, se consolidaron las caracteristicas locales en lugares dond la vida diaria iba encontrando su afán, al compás de este intenso intercambio comercial y por supuesto transcultura.

Era compleja y vital la dinámica de ese movimiento de migraciones y comercio entre continentes e islas. Aparte de los grandes barcos mercantes que llevaban y tralan los biens e insumos, existian en tierra los llamados almacenes, dond se vendian articulos para suplir nel mudado desde muchos sitios alrededor del mundo.

trañ ahorá olvidado puerto de Greytown, en el río San Juan, hacia el interior de la recien declarada indepen diente República de Costa Rica, entonces su hogar. Du-

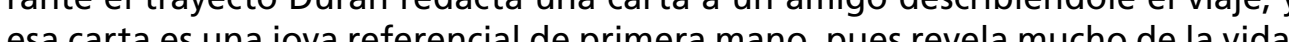
esa carta es " "espritu de la eia de primera mano, pues revela mucho de la vida

"Moin no deberia llamarse propiamente puerto, pues es una costa corrida sin fondeadero seguro ni bahía medianamente abrigada; pero en este siglo de po-
sitivismo y de movimiento comercial, el injenio humano encuentra praderosos vehículos de transporte en aquellos lugares en donde nuestros antepasados no habrían osado arribar en un buque de grandes dimenciones. Sin embargo pequenos botes y miserables lanchas cargadas con articulos de consumo, cruzan da." Durán S. Luis. (2013). Viaje Costa Rica 1857 de Uladistoo Dún. Revista Herencia Vol. 26 (1 y 2), 111-126, 2013.

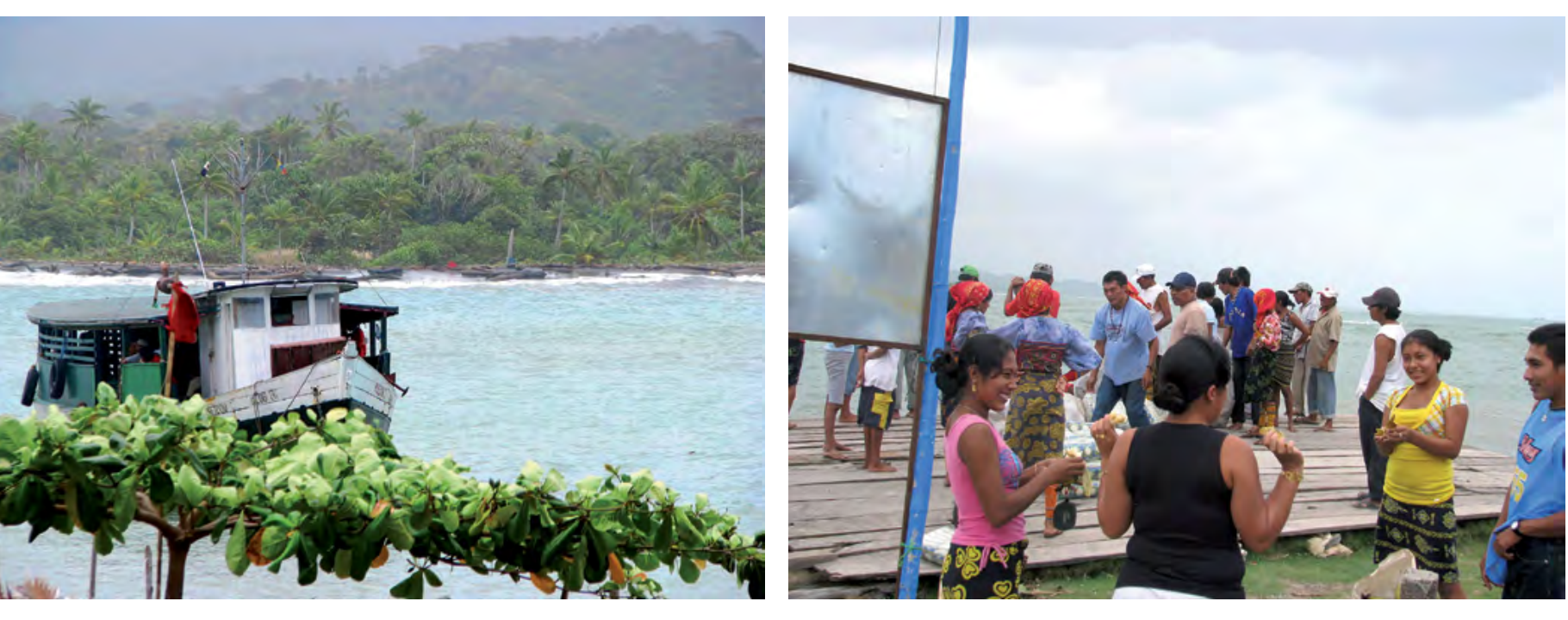
Fotos 1a. Barcaza almacén en su recorrido rutinario entre Cartagena y las Islas de Guna Vala. 1b.Desembarco de mercaderías
Isla de Niadup, 2009. Carolina Jiménez A.
Cocina e historia

La cocina es cultura si refleja historia, origen, pasado migratorio, trayectoria y dinámicas de asentamiento, o de intercambio, procesos de adaptación, técnicas culinarias, empleo de ingredientes, en fin, costumbres y tradiciones de los diferentes pueblos involucrados, y más aún si como corolario brinda además nuevas y valiosas mezclas y productos culturales exitosos, como los surgidos durante los pasados siglos de encuentros y uniones, intercambios y compleja formación. La naturaleza plena y fértil, predominante tanto en litorales como en las islas, acogió todo lo nuevo y surgío esa fusión culinaria singular que brinda nutrición adecuada al clima y ha sido elaborada por tradición con los ingredientes que la tierra y la mar proveen, unidos con buen aliño y el esmero de la cuchara que disfruta complaciendose en el condimento, el aporte de una fuerte dosis de ingenio y carisma, la apariencia que realza el apeticoso colonido tropical y el matiz A pacteristico e inigualable calorcito y picor de los chiles nativos.

A pesar del pasado drastico y extravagante, las transformaciones más profundas de esta zona caribona mundiles y finar mundiales y finalmenter la marca al final definitivo de la gran era del Caribe, y ese tránsito muétimo carac terístico, termina su papel principal en este lado del globo. En los últimos añosencricos (los principa les atractivos; se le promociona como a un paráso gastronómico natura principa-

Como bien dice el Secretario General de la Asociación de Estados del Caribe $(\mathrm{AEC})$, el Sr. Alfonso Múnera, en la inauguración de la Fiesta del Fuego del Festival del Caribe de Cuba, "la cultura resulta vital para unir al Caribe en su divercomo (Caribe" (Múnera, 2105); este festival, que es para compartir y dianos como para expé "' (Mún del año 2016 a Costa Rica.

Testimonio inglés, ingleses migrantes del S XVII

La familia inglesa de Daniel Walter Sargent Vega, migró a América a mediados del SXVII, cuando dejaron el área de Liverpool, en Inglaterra y emprendieron su viaje hasta Main, en Masachussets, al norte de los Estados Unidos, ahí se establecieron hasta el comienzo de la Guerra Civil entre los Partidos Demócratas y Republicanos, hacia 1775, cuando algunos de los miembros del grupo familiar entraron en desavenencias pues no querían ser republicanos, querían seguir perteneciendo al sistema monárquico inglés. La familia se dividió y una parte se quedó en Estados la oleada de migrantes que se fueron hacia Las Bahamas, para continuar perteneciendo a la Mancomunidad de Naciones de la Corona Británica (British Commonwealth of Nations); ahí nació su abuelo, su padre, y los dos hermanos de su papá, todos vivieron en la idílica Isla de Inagua, en Matthew Town.

Un tío suyo se preparó como ingeniero civil,-lucrativa profesión en esa época de crecimiento y auge tecnológico-, y trabajó en la construcción del ferrocarril de Santa Marta, Colombia; su padre, Daniel Archibald Sargent Nairn, también fue vivir a Colombia, donde pasó a formar parte de los empleados con mejor rango, dentro de 
la altamente jerarquizada planilla laboral de la gran empresa multinacional United Fruit Company, laborando en fincas de café, hasta que "La Compañía" lo envió a las bananeras de Costa Rica; llegó a Limón el día 2 de febrero de 1911 y compró una finca de 7 hectáreas en Matama, cerca de Westfalia y el Río Banano, lugar dond don Daniel, hijo, vive hoy con su esposa Dorita, oriunda de Tilarán.

Don Daniel recuerda que la mayoria de los migrantes que llegaban a la zona, eran personas de caracter aventurero, "que venian casi sin dinero pero que creían que estar aqui era la bonanza", y que aunque no encontraran el exito monetario que tal vez originalmente buscaron, si tenian una buena calidad de vida, una bien upapá nunca la na puraza misma proveía mos considera que se vivia bien- "papá nunca hizo plata, pero nunca vivimos mal, siempre vivimos muy acomóados y nos dábamos el lujo de tener buenos caballos y además, como de á era, como decimos aqul, emo deado 'rayado', queriendo decir, empleado de alto rango, teníamos privilegios, yo estudié en la escuela primaria que tenía ron que ponerme un maestro para que me enseñara español porque hablaba man que un un 1940 - "s " hant mucho icás, no inglés gringo, sino, inglés ingés" - refi-

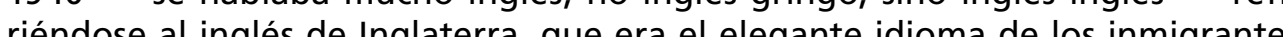
de porque en Limón había una colonia grande de alemanes, en todo Limón, tanto así que en Westfalia, - nombre dado en honor a esa provincia al Limón, tantón hoy existe un monumento, oculto y totalmente desconocido, que fue levantado en agradecimiento a uno de los administradores de la Finc Westfolia, 1,000 hérérs dadas en connosín a unos alemanes de apellido Maver." -

Otra colonia numerosa en Limón era la de los ciudadanos gallegos (españoles), están los Acuña, cuya descendencia llega hasta hoy, y los González, todavía con muchas tierras; era una época en que Limón era "blanco blanco o negro negro, no hab́a pañas", pañas es el ciudadano criollo actual en eo b́ co o nogro negro, no nes, como los Niehaus, los Schroeder o Gigler y los Freitag, y los franceses, como los

Foto 2 .
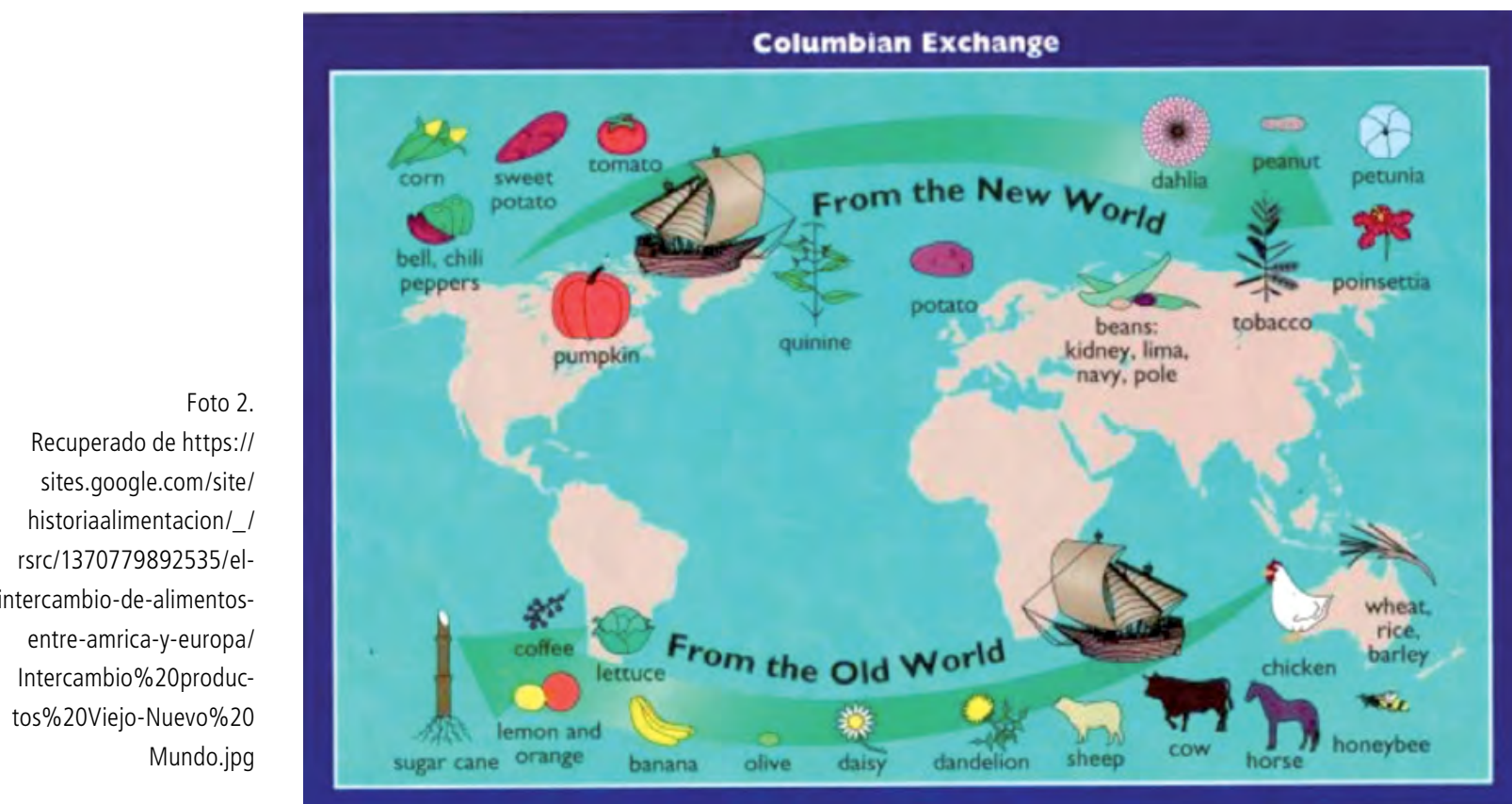

Laubert, quienes tenían una fábrica de "helados de palito". Destaca a Limón como a una cuidad próspera, la describe inmaculadamente limpia ya a las 10 de la mañana y recuerda que las familias se mantenían dentro de su núcleo y grupo social.

Asertivo y muy interesante también es el aporte de don Daniel al aclarar que muchas de las recetas que desde hace algún tiempo se han etiquetado como comida afrocaribeña, son recetas que en realidad tienen influencias del contacto con personas de otras nacionalidades, como la parte de fuerte herencia inglesa, dice el, facil de entender si recordamos que generalmente eran personas afroantillanas quienes servian a familias inglesas y fueron aprendiendo las recetas de estos senores. Muchos de ellos llegaron a Puerto Limón, hacia 1870 más o menos, ción del ferrocarril; el General Tomás Guardia estaba negociando la construccón del ferrón i hán la emancipacion ya habia pasado, y al igual que los blancos, muchos de ellos pensaron que aqui "estaba la plata cayenndoles por las ventanas, pensaron que ron porque así se llamaba Old Harbor, en inglés y no Puerto Viejo, en e volvieron, porque asi se llamaba Old Harbor, en inglés y no Puerto Viejo, en español, crigin a las poblaciones, tendenci opina que ńs fuerte entre los pueblos en la búsqua a por rencontra $y$ afianzar la cultura propia.

Esidionar las comidas andes ojos ingleses ticos gestos, cada vez más agitados y sugerentes, hipnotizando nuña con enfáque sigue con atención sus inmensas manos de hombre trabajador $y$ hirada ósea fuerte y alargada. Para los días entre semana rocuerda que se comía senci-

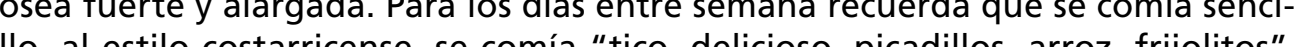
mucha verdura que traía desde Cartago un hortelano de una familia Damián 作 todavía conserva, ahora de 10 hectáreas.

Él creció entre la cotidianeidad de uno más de los campamentos que se desarrollaban alrededor de las plantaciones de "La Compañía" y además de esos recuerdos especiales del contacto entre muy variadas nacionalidades y del tránsito de personas en busca de progreso y negocio, atesora dos recuerdos especiales, la exuberancia de la naturaleza en sus años de mozo, tanto animal que había y cómo sobresalía en la región la característica del aporte afro, en su manera de cocinar y en saber dar un toque particular a las recetas que habín ido aprendiendo; para él fue bellísimo traer a la memoria a las guapas vecinas afro caribeñas caminando con ritmo y porte elegante todos los domingos en la mañana, en su camino a la iglesia.

Opina que la comida de antes estaba espcialmente influida por el estilo afro isleño, pues lo usual era que las personas "pudientes", es decir, económicamente estables, contrataran cocineras afrocaribeñas, recuerda que como costumbre generalizada se disfrutaba el almuerzo del domingo en familia, siempre con un buen plato de Rice and beans preparado con gandul, un frijol rojo y redondo diferente al que se usa en este tiempo.

El rondón era un platillo muy apetecido, lo preparaban sobre todo los señores negros mayores, casi siempre los domingos, y para eso se juntaban varios hombres en un patio y entonces lo primero que se hacía era mandar a alguien adónde el chino a buscar una lata de manteca, "-porque siempre había un chino-", bromea don Daniel con su potente voz, "-o que corrieran a uno de los almacenes de "La Compañía"-, siempre muy bien surtidos, al estilo gringo, como los llamados "country store", -o tienda de campo-, donde había de todo, pantalones, botas, abarrotes, implementos de trabajo-". 
Él es parlante nativo del inglés de Inglaterra, pero también habla el broken English, o el inglés local de nuestro Caribe, así que espontáneamente continua la narración usando el idioma en el que recuer unos amigos querían beber guaro y entonces usualmente la trama iba asi:

-Lord let me cook something man.

-What do you wan fi cook?

-Let's make a rondón.

-All right you get thi pan.

-All right I get thi pan.

- Is clean?

-Yeah man, thi pan is clean.

-Oh right then, you griate up thi coconut and you run down and bring some hile, run down and bring thi chicken, run down and get some malanga and some yucca and some plantain.

-Pero eso sí - agrega enfático y divirtiéndose mucho- "la gallina debía ser robada", - y repite aún más eufóricamente - "la gallina tiene que ser robada" robada", -y repite aún más
"termina carcajeándose".

El detalle del uso de la lata de manteca agrega una importante variante a esta receta del rondón, ahora realizado rudimentariamente dentro de un contexto blecidas por "La Compañía" desparecen. Otro aspecto muy interesante es que

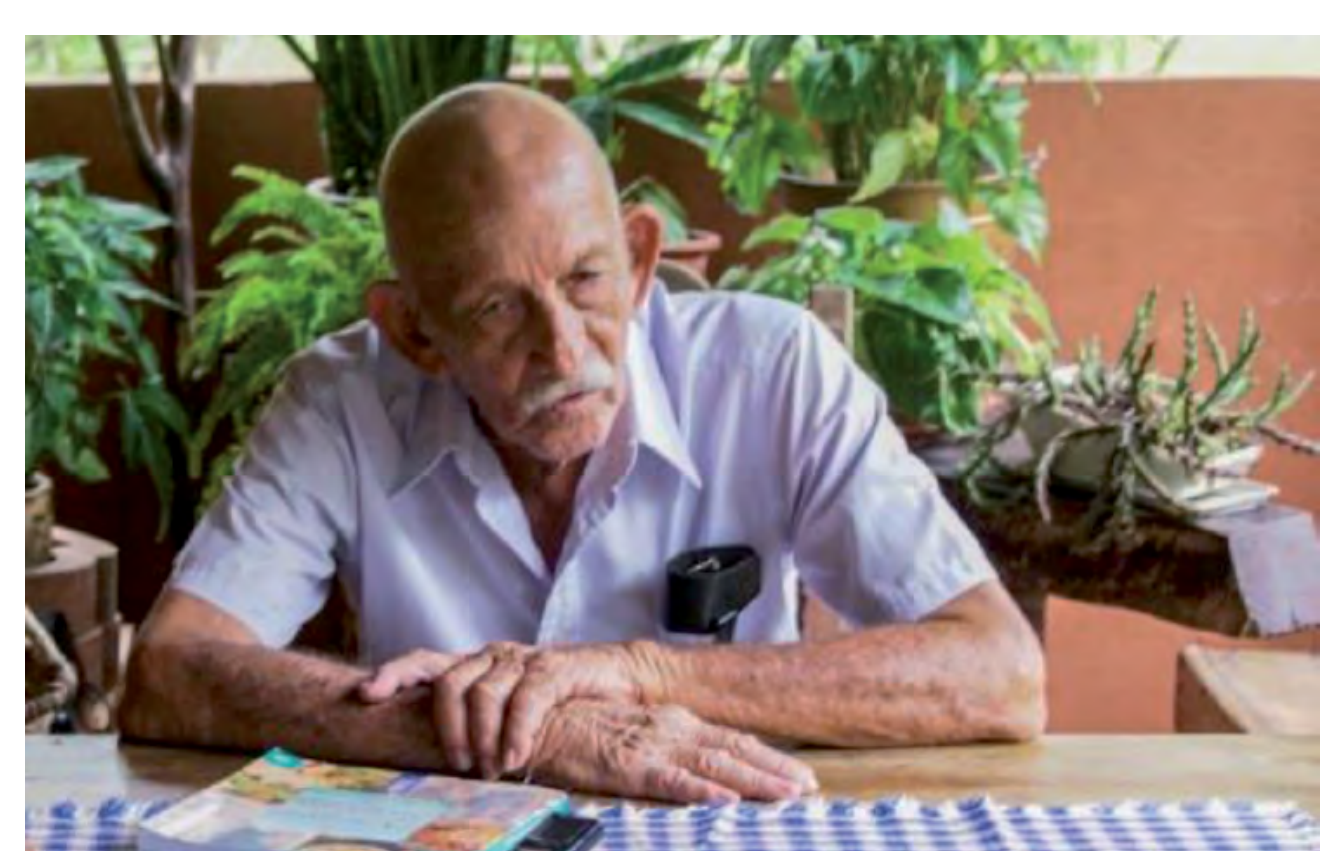

mencione el "robar una gallina", porque suponíamos que un rondown no lleva pollo o gallina, pero él afirma que "se le ponía de todo", y repite "en realidad se le ponía de todo lo que fueran carnes, se le ponía pescado, se le ponía carne salada y uno de los ingredientes más importantes, el chile, no era el panameño que se usaba, era el Scotch Bonnet, que ya no existe, ya ese se perdio, era un chile parecido al panameno, pero era como un gorro aplastado, por eso le dicen Bonnet, porque Bonnet es un gorrito, y era amarillo, amarillo, amarillo y tenía

\section{Scotch Bonnet o Chile Jamaica}

Los Scotch Bonnet pertenecen a una variedad de chile picante esencial en muchas comidas del caribe antillano y costero, $\mathrm{e}$ indispensables en algunas recetas caracteristicas de la comida

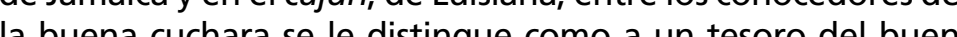
sabor; del sce sonnet costa 列 más caliente y popular de todas las variedades que el chile más caliente y popular de todas las variedades que están en viveres y dar servicios de catering de las Islas Antillanas, a nivel mundial, distribuyen el Scotch Bonnet. El "Scotch bon, a nitambién es conocido como Chile Jamaica y " no es cannet"

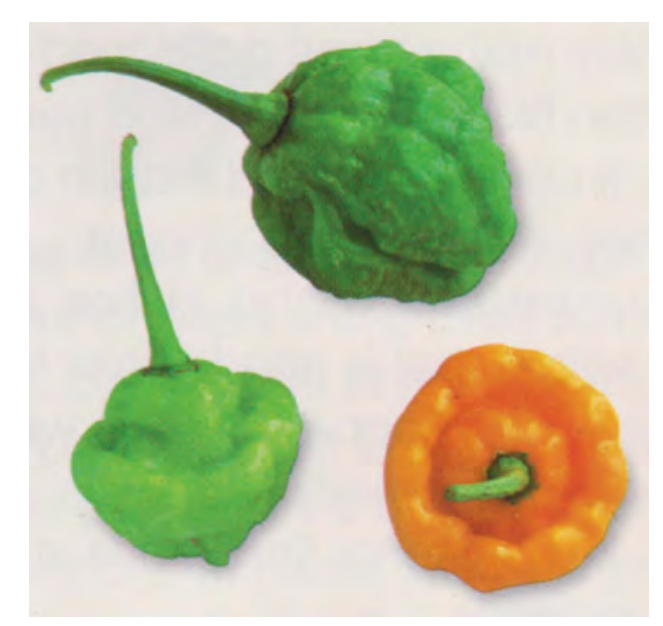

\section{Herencias culinarias e influencia de Jamaica}

Como bien se sabe a la costa caribeña costarricense llegaron a trabajar obreros de varias Islas y pueblos costeros del Caribe, sobre todo de Jamaica, isla de las Antillas Mayores, y la comida de Jamaica es reconocida como a una deliciosa combinación de ingredientes y estilos culinarios, provenientes de las muchas nalargo de su historia. En el año 1997 la oficina de Turismo de Jamaica dice:

"Los indios Arawaks dieron a nuestra isla este nombre Xaymaca.

Y, durante años la tuvieron sólo para ellos.

Pero con el paso del tiempo, a lo largo de los siglos, el mundo entero vino y se quedó.

E hicieron de nosotros lo que somos.

Vinieron desde España y nos dieron nombres como Ocho Ríos y Río Grande. Y de Inglaterra con sus leyes y su idioma. Vinieron de África con su rica cultura vitalidad. De Portugal con su antigua tradición judía. Y de china e India, de Siria y Nepal, De Escocia y Francia.

Y todos ellos tuvieron hijos e hijas Jamaicanos.
Foto 4. DeMers John Fuss Eduardo. (2005).
Authentic Recipes from Authentic Recipes fro
Jamaica. Singapore: Periplus Editions. 
Así que aunque nuestro plato nacional es el Akee procedente de Ghana, servido con pescado salado en todas partes, nuestro menú incluye wonton frito, fettucine, fondue de boeuf y té cerasee.

Hoy, quizá usted podrá ver por qué nuestro lema es "Out of Many, One People", "De muchos uno"." (Jamaica Tourist Board, 1997: p. 1)

La siembra y el cultivo de la tierra ofreció una gastronomía balanceada a los afrodescendientes y ellos nunca dejaron de ser agricultores, a pesar de épocas adversas, los recursos de la tierra son aún el sustento diario y se mantien la costumbre del mercado semanal, práctica ancestral aprendida en el suelo madre, en la tierra de los leones y prentes soles de sus antepasados. Jamaica crecio con un desarrollo sostenible, estable y planticado, gracias a las huertas caseras como sistena de vida tradicional, se mantiene fuerte tambien la usanza de levantar pequeños puestos a orillas de los caminos, o donde hay transito das a

La lama los ingredientes naturales intensificar su sabor, el sabor del Nuevo permitir sabor del Caribe, el sabor de la mezcla y de la diversidad, pues, el origen de sabile y de sus usos culinarios, por ejemplo, es del Nuevo Mundo, tambiénen de ch peibaye son nativos del continente indígena; la costumbre, tambien la yuca los alimentos es española y francesa, pero éstos usaban las especies que buscaban en ll plicadas mezclas de curry y los sabrosos caldos de cocinar lento y con las comcon influencia de la India; el gusto por la carne de cerdo agridulce y las carnes profusamente condimentadas, servidas en su salsa bronceada, se adquieres profusamente conda ta y de libaneses, y se asimilaron costumbres gastronómicas de una antigua coria, yia Judí; plátanos, bananos y fruta de pan, fueron llevados, y un ingrediente primordial, el coco, se invitó solito al banquete, al llegar flotando en el mar desde su origen incierto.

Los africanos por su parte llevaron también el calalú, o kollilu, callaloo; la nuez moscada y el popular akee, que se vende en grandes canastos en las calles; panes y flanes honran antepasados ingleses y franceses, las frutas tropicales tienen su presencia añadiendo lo piña sabor la pina es nativa de Jamaica, $y$ todos los viejos y nuevos ingredientes se han ido uniendo y reinventado, hasta coribeña, siendo la afrocaribeña una canibeñ, siendo la afrocar

La comida de Jamaica es producto de una herencia cultural muy diversa, su conida cuenta la historia de su gente" (DeM curs y Fuss, 2005: p. 4), Authentic recipes from Jamo tica atribuyen la singulomidar ellos sabor de la comida de Jamica a compleja diversidad étnica. Entrado ya el siglo XX el pueblo de Jamaica recoel siglo XX el pueblo de Jamaica recotos británicos ya habí sido substituido por la certeza de sentirse isleño, de ser persona poseedora de la personalidad amaiquina un "Jamaican man", y en Iñ 1962 Jamaica queda libre de Inglaterra. La nueva nación rescata la multiplicidad de su origen cultura cuando se iza su bandera la cual posee un colorido escudo que expone los elementos simbólicos de la patria.

La comida afro limonense muestra y mantiene las herencias culinarias de Jamaica. En el Caribe Sur costarricense una excusa perfecta para disfrutar de toda la exquisitez y beneficios del "soul food", es acercarse a los puestos de comida ocasionales que se montan para los días de fiesta nacional, como

para la última semana del año y en la Semana Santa, que es cuando los vecinos afrodescendientes de Old Harbor y de Manzanillo preparan platillos tradicionales, cuidadosamente elaborados, para ofrecer en los puestos ocasionales; se prepara el rundown, el pargo en salsa caribeña, patacones, "scovich" de macarela, Jerk Chicken, o el cambute en leche de coco, que con suerte podríamos encontrar en alguno de los puestos de Manzanillo.
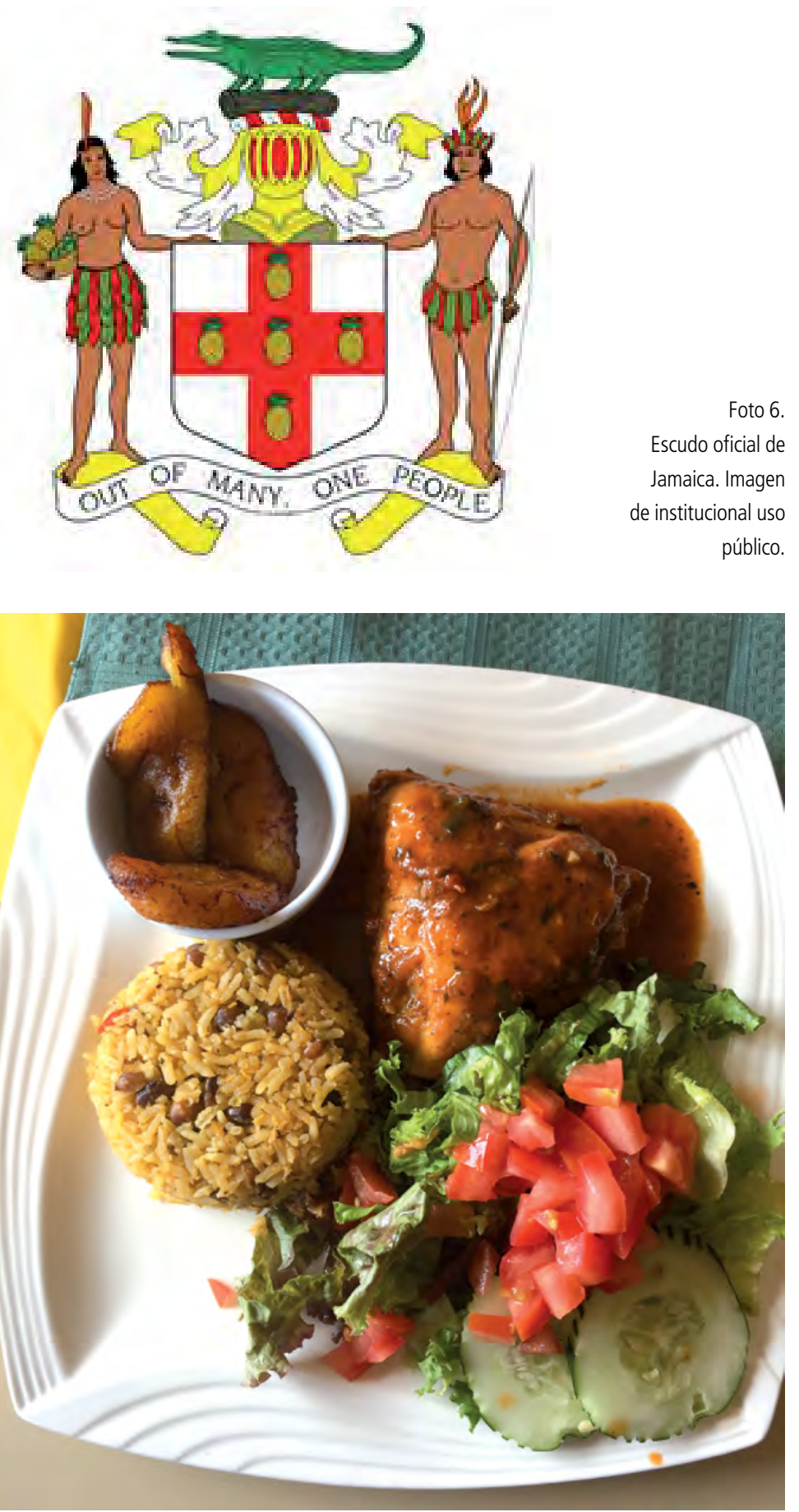

Foto 7
con pollo

\& beans con pollo

de "Baby

$\square 7$ GEZZADA.

$\square$ COCA BREAD.

7 FRIED BAMMY..

GRIED PLANTAIN

面 CHESEE CAKE 
Podemos visitar a dos herederos directos del feeling Jamaica, al rasta "Baby" quien tiene su puesto en el pueblo de Old Harbor, los domingos, cerca del punto conocido como "Salsa Brava", y vende un delicioso Rice \& Beans con pollo o pescado en leche de coco.

Sábados y domingos, en la playa llamada "Beach Break", en Pirripli, Cocles, está Cristián con su inconfundible "carrito", sirviendo platillos sensacionales, como el Jerk Chicken, delicioso pollo marinado con especies a su estilo" y cocinado lentamente a la parrilla, con el cuido personal de Cristián, quien lo baña constantente con su salsa Jerk personal hasta servirlo doradito, acompañado por rice \& beans, yuca amaillita y Coleslaw, su ensalada con receta secreta, que lleva y azúcar morena.
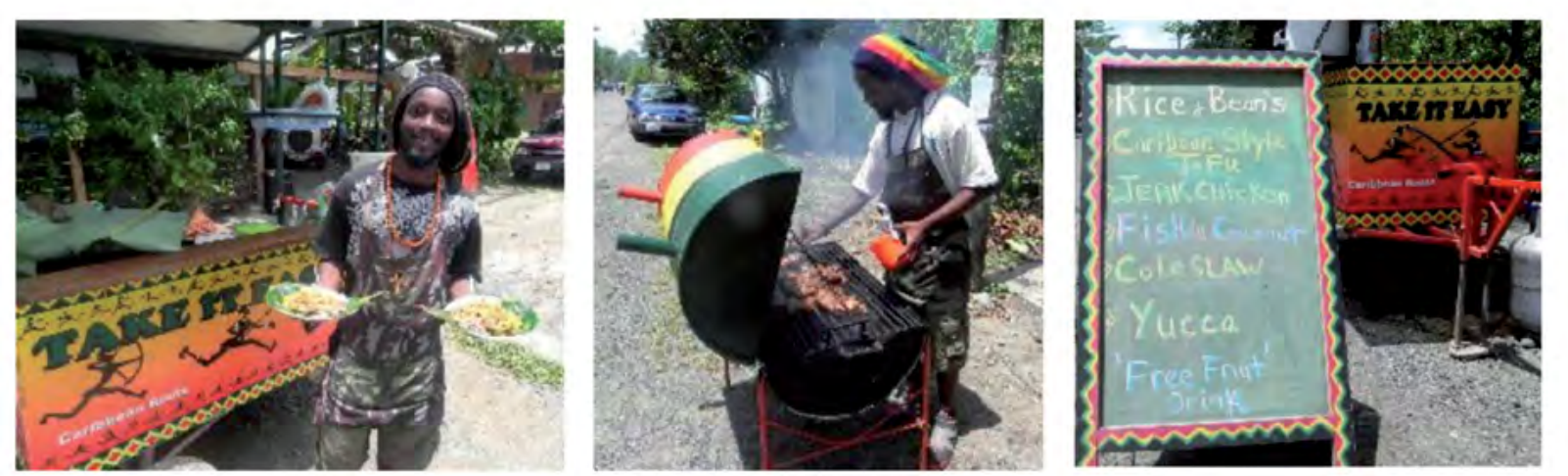

Foto 8. Tirza Morales Sánchez preparando picadillo de bananito "Soul Food" y 3 Recetas Bribris

Tirza Morales siente que es Bribri en su corazón, su padre es Bribri, pero ella no forma parte del clan de su padre, el clan Turuwak, porque se pertenece al clan por la linea materna, solo su padre pertenece al clan de su abuela, sin embargo, y sobre todo por los años que pudo compartir con su abuela Bribri en Yorkin de Talamanca, es que ella pudo descubrir en sí misma una identidad que ahora lucha por mantener y valorar, tanto en su trabajo con turismo como dentro de la intimidad familiar. feridas de mantiene ella siempre "rondándole la cabeza", porque eran sus prela visitaba por varios días.

\section{Tubérculos con pescado de río}

Sentarse sobre piedras grandes y de superficie suave y bondadosa en un remanso de agua fresca y transparente del río Yorkín, y recordar la voz de su abuelita contarle sobre historia o plantas medicinales, es parte de esta receta. Su abuela, Soyla Morales Morales, con 82 años, la entretenía transmitiéndole sabiduría mientras
sostenía la flecha de chonta, elaborada especialmente para pescar; lo asombroso y fascinante para Tirza era el momento cuando una señora de esa edad, que hasta y fascinante para Tirza era el momento cuando una señora de esa edad, que hasta otro y en el segundo menos esperado, saz, silbaba la flecha y la abuela la volvía a sacar del agua con un veloz movimiento y un barbudo coleando.

Ahí mismo en el río se limpiaba la pesca y "-abuelita le hacía cortes longitudinales a cada lado del lomo-", luego volvían a casa y en un ollita se montaba "una cama" con bananito verde, trozos de ñame y yuca pelados, se llevan a hervir con suficiente agua y un poquito de sal y sobre ellos se coloca el pescado entero, envuelto en hoja de bijagua verde. Tirza considera que "era una especie de cocina al vapor, pues la abuela tambien tapaba la olla con la tradicional hoja de bijagua, pero de esas que son verdes por ambos lados, que son las especiales en la cocina y permiten una cocción lenta y uniforme, que concentra el sabor natural"

Por supuesto que ante un platilo de estos debemos ser capaces de reconocer la magia de la biljagua, el toque especial e inconfundible dejado por su aroma y gusto, tan sutiles, unicos, básicos y reales, como el que también agrega el cocinar con leña, cuando el atice sube el vapory el aroma del ahumado natural refuerza los delicados sabores originales de los ingredientes, los cuales combinan muy bien con la livion-

\section{Picadillo de bananito verde con Calalú}

Una de las delicias de la comida unida a las fuentes domésticas, es poder tener muy cerca los ingredientes frescos, crecidos naturalmente. La comida original y la más sana es ésta. De nuevo el ingenio la hizo apetecible y variada.

ara esta receta se deben buscar unos bananitos verdes y lavarlos con cáscara, a 列 verde Se sabe que están listos porque la cáscara se raja sola por el otro de bijagua veriran del fuego, se les quita el agua caliente y se dejan enfriar. Mientas tano, se les quita el agua caliente yse deja sol

Molve cúrcuma, cuando la y los tajadeaba, poní un comal en el fuego y vertía en el comal caliente un
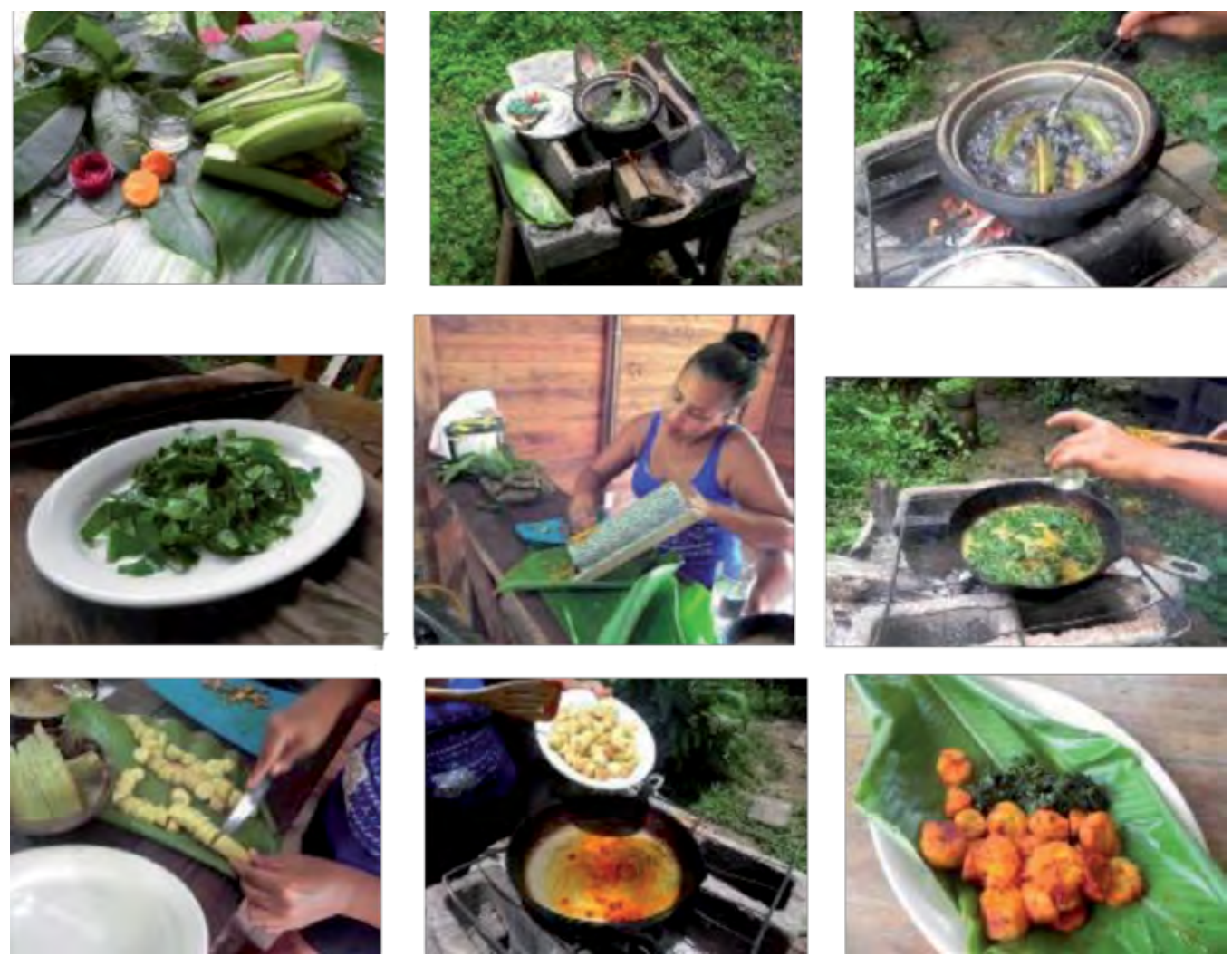
Sánchez preparando picadillo de bananito verde con calalie. 
poquito de aceite de coco, -común en la zona y muchas veces casero también-, a continuación le agregaba un poco de achiote de la casa y lo mezclaba, luego agregaba el bananito tajadeado y con su cuchara de palo lo mezclaba despacio y con atención; cuando ya el picadillo tomaba un tono rojo-anaranjado bien uniforme se veía muy apetitoso, retiraba la sartén del fuego y servía el picadillo en los platos sobre hojas soasadas, o lavadas, de bijagua verde.

De inmediato rallaba un poquito de cúrcuma y picaba juntas las mejores hojas de calalú; volvía a poner el comal en el fuego, estando el comal caliente se le agrega un poquito de agua, al calentar se le agrega cúrcuma rallada y se deja hervir cuando el agua tiene un color naranja caracteristico y la cúrcuma cocinó un poco, se le agrega el calú empapandolo bien en el agua para que tome color y sabor: con movimiento circular, se mezclan para uniformar el sabor y se deja cone coco con moviniento cicular, se mezclan para uniformar el sabor y se deja concentrar; se retira del fuego al evaporarse el agua y se sirven acompando el picadilo de comida verdader

Comida verdadera que utiliza sabiamente los recursos naturales a nuestro alcan

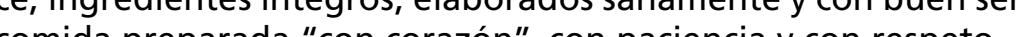
comida preparada "con corazón", con paciencia y con respeto.

\section{Refresco de pejibaye y bananito criollo}

Al menos media hora tomaba a doña Soyla preparar una de las bebidas que acostumbraba servirle a su nieta con estas comidas caseras tan tradicionales.

Como la abuela siempre tenía racimos de pejibaye, -llevados a Talamanca por los Misquitos-, y bananitos criollos en el patio trasero, solamente salía a escoger unos pejibayes, pero de los más maduritos, porque otros, más verdes, o pintones, se guardaban para otras cosas; los ponía a cocinar con agua y sin sal, durante unos 20 minutos.

Cuando estaban fríos los pelaba y los rayaba dentro de un pichel, les agregaba un . reposar: mientras tanto pelaba unos 6 bananitos criollos, también de los bien ma duritos, y en un recipiente y ayudada por una piedra de rio, -de canto redondeado y superficie suave-, machacaba intensamente los bananitos hasta convertirlos en una masita uniforme y suave, la cual agregaba al agua de pejibaye y mezclaba muy bien con el molinillo, terminaba agregando un poquito más de agua.zos La combinación es deliciosa pues las dos texturas se unen muy bien y agrega un sabor dulce y una suavidad especial al gusto almidonado que aporta pejibaye. Por supuesto, Tirza recuerda divertida que después de tomar un vaso de esta bebida ya no querían comer nada más.

\section{Bibliografía}

Archivo Nacional. (2011). El Álbum de Figueroa: Un viaje por las páginas del tiempo. San, José. Costa Rica: EDUPUC. Editoriales Universitarias Públicas Costarricenses.

Borge, Carlos; Castillo, Roberto. (1997). Cultura y conservación en la Talamanca indígena. San José, Costa Rica: EUNED.
Bourgois, Philippe. (1994). Banano, etnia y lucha social en Centroamérica. San José, Costa Rica: Editorial Departamento Ecuménico de Investigaciones (DEI)

Boza Villareal. (2014). La frontera indígena de la Gran Talamanca. San José, Costa Rica: EDUPUC. Editoriales Universitarias Públicas Costarricenses.

Cabanillas, Berta. (1973). El puertorriqueño y su alimentación a través de su historia (Siglos XVI al XIX) San Juan, Puerto Rico: Instituto de Cultura Puertorriqueña.

DeMers John, Fuss Eduardo. (2005). Authentic Recipes from Jamaica. Singapore: Periplus Editions.

Díaz P., Héctor. (2006). El laberinto de la identidad. Cronología histórica de la Costa Atlántica de Nicaragua. México D.F., UNAM. Universidad Nacional Autónoma de Aéxico.

Jiménez A., Carolina. Escape a Kuna Yala. San José, Costa Rica: EUNED

Jiménez A., Carolina. (2007). Sazonando recuerdos. Anécdotas, historia y recetas de cocina de Puerto Viejo de Talamanca. San José, Costa Rica: EUNED.

León Jorge, Álvarez P. Luis J., Sánchez V. Pablo E. (1999). Los nombres comunes de las plantas en Costa Rica. Universidad de Texas, USA; Editorial Fundación UNA.

Malmierca, I. (2000). Cronología del Caribe.Habana, Cuba:SI-MAR.

Mira C., Esteban. (2010). La Española, epicentro del Caribe en el siglo XVI. Academia Dominicana de la Historia. Volumen XCL, Santo Domingo, República Dominicana: Editorial Búho.

Nikolic Mona.( 2015). Identität in der Küche. Kulturelle Globalisierung und regionaleTraditionen in Costa Rica. Bielefeld, Alemania transcript.

Pereira A., Boxill Ian, Maerk Johannes. (2002). Tourism, development and natural resources in the Caribbean. D.F. México: Editorial Plaza y Valdés.

\section{Consultas en internet}

Durán S., Luis Armando. (2013). VIAJE A COSTA RICA EN 1857 de Uladislao Durán. Revista Herencia Vol. 26 (1 y 2), 111-126, 2013. Páginas recuperadas. Fecha consulta 23-07-15. Disponible en: http://revistas. ucr.ac.cr/index php/herencia/article/ view/19043/19132

Embajada de Jamaica. (2015). Acerca de Jamaica: Símbolos Patrios. Bandera Nacional Escudo Nacional Himno Nacional. Fecha consulta 27-07-15. Disponible en: http:// www.embajadadejamaica.com/5\%C3\%ADmbolos\%20Patrios-dejamaica-12. html\#.VcKCyfl_NBd

Caribbean \& Americas News Digital. (2015). Fiesta del Fuego: Vital la cultura para unir al Caribe en su diversidad. Noticias de Turismo. Fecha de consulta: 23.07.15. 
Disponible en: http://www.caribbeannewsdigital.com/noticia/xxxv-fiesta-delfuego-vital-la-cultura-para-unir-al-caribe-en-su-diversidad

Cocina de hogar.com (2010). Recetas de cocina sencillas. Chiles ajíes y pimientos. Fecha de consulta: 21.07.15. Disponible en: http://www.cocinadehogar.com/chilesajies-y-pimientos.html

The world of chillies. Hot flavours from around the world for you to grow and taste Fecha de consulta: 03.08.15. Disponible en: http://www.worldofchillies.com/chiIlies_gallery/pods-gallerypluskit/pods-gallery-pluskit.html

Caribbean groceries. Caribbean Trini Catering Services. Fecha de consulta: 21.07.15. Disponible en: http://www.caribbeangroceries.com/index.php/scotch-bonnetpeppers.html

Alden Lori. (1996-2005). The cook's treasures. Fresh Chile Peppers. Virtual cooking encyclopedia. Fecha de consulta: 22.07.15. Disponible en: http://www.foodsubs. com/Chilefre.html 